\title{
Phase I/II Study of Temozolomide Plus Nimustine Chemotherapy for Recurrent Malignant Gliomas: Kyoto Neuro-oncology Group
}

\author{
Tomokazu AOKI, ${ }^{1}$ Yoshiki ARAKAWA,${ }^{2}$ Tetsuya UEBA, ${ }^{3}$ Masashi OdA, ${ }^{4}$ \\ Namiko NishIDA, ${ }^{5}$ Yukinori AKIYAMA, ${ }^{6}$ Tetsuya TsuKaHARA, ${ }^{1}$ \\ Koichi IWASAKI, ${ }^{5}$ Nobuhiro MIKUNI, ${ }^{6}$ and Susumu MIYAMOTO ${ }^{2}$
}

${ }^{1}$ Department of Neurosurgery, National Hospital Organization, Kyoto Medical Center, Kyoto, Kyoto, Japan;

${ }^{2}$ Department of Neurosurgery, Graduate School of Medicine,

Kyoto University, Kyoto, Kyoto, Japan;

${ }^{3}$ Department of Neurosurgery, Kochi Medical School, Kochi University, Nankoku, Kochi, Japan;

${ }^{4}$ Department of Neurosurgery, National Hospital Organization,

Himeji Medical Center, Himeji, Hyogo, Japan;

${ }^{5}$ Department of Neurosurgery, Kitano Hospital Medical Research Institute, Osaka, Osaka, Japan; ${ }^{6}$ Department of Neurosurgery, Sapporo Medical University, Sapporo, Hokkaido, Japan;

\begin{abstract}
The objective of this phase I/II study was to examine the efficacy and toxicity profile of temozolomide (TMZ) plus nimustine (ACNU). Patients who had received a standard radiotherapy with one or two previous chemoregimens were enrolled. In phase I, the maximum-tolerated dose (MTD) by TMZ (150 mg/m $/ \mathrm{m}^{2} \mathrm{day}$ ) (Day 1-5) plus various doses of ACNU (30,35, 40, $45 \mathrm{mg} / \mathrm{m}^{2} /$ day) (Day 15) per 4 weeks was defined on a standard $3+3$ design. In phase II, these therapeutic activity and safety of this regimen were evaluated. Forty-nine eligible patients were enrolled. The median age was 50 years-old. Eighty percent had a KPS of 70-100. Histologies were glioblastoma $(73 \%)$, anaplastic astrocytoma $(22 \%)$, anaplastic oligodendroglioma ( $4 \%)$. In phase I, 15 patients were treated at four cohorts by TMZ plus ACNU. MTD was TMZ $\left(150 \mathrm{mg} / \mathrm{m}^{2}\right)$ plus ACNU $\left(40 \mathrm{mg} / \mathrm{m}^{2}\right)$. In phase II, 40 patients were treated at the dose of cohort 3 (MTD). Thirty-five percent of patients experienced grade 3 or 4 toxicities, mainly hematologic. The overall response rate was $11 \%$ (4/37). Sixty-eight percent (25/37) had stable disease. Twenty-two percent (8/37) showed progression. Progression-free survival (PFS) rates at 6 and 12 months were $24 \%$ (95\% CI, 12-35\%) and 8\% (95\% CI, 4-15\%). Median PFS was 13 months (95\% CI, 9.2-17.2 months). Overall survival (OS) at 6 and 12 were $78 \%(95 \% \mathrm{CI}, 67-89 \%)$ and $49 \%(95 \%$ CI, 33-57\%). Median OS was 11.8 months (95\% CI, 8.2-14.5 months). This phase I/II study showed a moderate toxicity in hematology and may has a promising efficacy in OS, without inferiority in PFS.
\end{abstract}

Key words: temozolomide, nimustine, recurrent malignant gliomas, phase I/II study

\section{Introduction}

Malignant gliomas are devastating malignancies, destroying cognitive functions in the brain, altering the personality of a human, and leading to death. Generally, a standard treatment of a newly diagnosed malignant gliomas usually consists of cytoreductive surgery followed by radiotherapy (RT) concomitant with TMZ therapy, ${ }^{11}$ though treatments for Grade 3 gliomas are controversial and have not being established. ${ }^{2,3)}$ The clinical benefit of adding bevacizumab

Received May 28, 2016; Accepted July 31, 2016 to the treatment is controversial. ${ }^{4-6,8)}$ Gliadel wafers also have been often used, if possible. ${ }^{8,9)}$ Despite the advent of multimodal treatments, this tumor always recurs within 1 or 2 years. Then, we don't have any established second-line treatments.

Nitrosoureas have been the mainstay of therapy, for example, ACNU, carmustine (BCUN) or lomustine (CCNU) until the advent of TMZ. ${ }^{10,11)}$ These have demonstrated an activity in malignant gliomas and are widely used for the treatment of malignant gliomas. ${ }^{12)}$ The rationale for the combination of these agents is that they may have synergistic activity due to TMZ's depletion of O6 alkylguanine-DNA 
alkyltransferase (AGT), the DNA repair enzyme that is believed to contribute to nitrosoureas resistance. ${ }^{13)}$

Phase II studies of BCNU or CCNU plus TMZ have been reported. ${ }^{11,14-16)}$ BCNU with TMZ have shown a strong toxicities and limited efficacy. ${ }^{11,14,16)}$ CCNU plus TMZ have shown a promising efficacy with a moderate tocicity. ${ }^{15)}$ But, ACNU plus TMZ have not been reported. Therefore, we tried the phase I/II study of TMZ plus ACNU chemotherapy.

\section{Patients and Methods}

\section{Eligibility for study participation}

Patients enrolled on this study had supratentorial anaplastic gliomas (AG) or glioblastoma (GBM) previously treated with surgery, a conventional radiotherapy (60 Gy), and one or two chemotherapyregimens. Tumor progression was confirmed on contrast-enhanced (CE) MR imaging. If radiation necrosis or pseudoprogression was suspected, spectroscopic MR imaging was performed to confirm the presence of viable cells. If mainly necrosis was noted in those who underwent repeat surgery for a recurrence, adjuvant chemotherapy was continued. Patients were required to be at least 18 years old, have a KPS score over 60, and have a life expectancy over 12 weeks. An interval over 12 weeks from the completion of radiotherapy, over 4 weeks from prior chemotherapy (6 weeks from a ACNU-based regimen), and over 2 weeks from salvage surgery had to have elapsed for the patient to be eligible for this study enrollment. Adequate laboratory values were also required, including a neutrophil count over $1500 / \mathrm{mm}^{3}$, platelet count over $100,000 / \mathrm{mm}^{3}$, transaminase and alkaline phosphatase levels under three times the upper limit of laboratory normal, and serum creatinine and bilirubin levels under 1.5 times the upper limit of laboratory normal. In addition, patients were not pregnant, had an uncontrolled infection, or had any prior malignancy. All patients signed informed consent according to the principles of the Declaration of Helsinki and the rules of good clinical practice. These institutional review boards at local participant hospitals in Japan, have approved the protocol. All histological slides were reviewed by an independent central neuropathologist in Kyoto University.

\section{Study design and treatment}

This was a dual-agent, open-label, phase I/II study. In phase I, eligible patients were enrolled and treated according to the schema in Fig. 1, using a standard $3+3$ design. ${ }^{17,18)}$ All patients were treated with a fixed dose of ACNU at $30 \mathrm{mg} / \mathrm{m}^{2}$ up to a maximum cumulative dose of $45 \mathrm{mg} / \mathrm{m}^{2}$. ACNU was given intravenously for about $30 \mathrm{~min}$. TMZ was orally administered on an empty stomach 30 min after antiemetic prophylaxis; redosing was not allowed if vomiting occurred. The fixed dose of TMZ was $150 \mathrm{mg} / \mathrm{m}^{2}$. TMZ was taken for 5 consecutive days (Day 1-5) followed by a 23-day rest period; one cycle was 28 days. ACNU was administered at day 14 on each cycle. A minimum of three patients and a maximum of 6 were enrolled per cohort. A dose-limiting toxicity (DLT) was defined as grade 3 or 4 nonhematologic or hematologic toxicity, based on the National Cancer Institute Common Toxicity Criteria (version 4), during cycle 1. If no DLTs were observed, treatment continued and three patients were treated in the subsequent cohort. However, if one of three patients experienced a DLT, another three patients were added at this cohort. If two of six patients experienced a DLT, this level was declared too toxic, and another six patients were added at the prior dose level. The maximal tolerated dose (MTD) was defined as the dose where $0 / 3$ or $1 / 6$ patients experienced a DLT (Fig. 1). No intrapatient dose escalation was permitted.

In phase II, the primary end point of this study was the percentage of PFS at 6 months (PFS-6). Secondary end points included the percentage of PFS at 3,12 , and 18 months; tumor response to treatment; overall survival; and time to disease progression. The regimen would be considered a success if at least $30 \%$ of enrolled patients responded to it, whereas the regimen would be considered ineffective if a success rate under $10 \%$ was observed. In the North Central Cancer Treatment Group (NCCTG) database of patients with recurrent GBM, the PFS-6 was $10 \% .^{19}$ Our design used 33 patients and had an alpha level of 0.04 and a power of 0.89 for detecting a true success probability of $30 \%$. The original sample size of the study was 37 (33 patients with four additional patients in case of drop-outs), and 40 patients were accrued initially. Forty patients treated at phase II dose were six patients from phase I portion and 34 patients from phase II. All patients had a complete physical examination and a CE MRI scan at baseline and before beginning each new cycle. Each patient had a complete blood count every week and electrolyte and liver function tests every 4 weeks. All the hematological toxicity from the previous course of chemotherapy had resolved to Grade 2 or less, and all nonhematological toxicity had recovered to either Grade 0 or 1. If sufficient recovery had not occurred, the subsequent course was delayed until these criteria were met. No dose escalation was allowed. A dose reduction of ACNU, from $40 \mathrm{mg} / \mathrm{m}^{2}$ (cohort 3) to $35 \mathrm{mg} / \mathrm{m}^{2}$ (cohort 2), for toxicity was permitted. Only two dose reductions, from $40 \mathrm{mg} / \mathrm{m}^{2}$ (cohort 3) via $35 \mathrm{mg} / \mathrm{m}^{2}$ (cohort 2) to $30 \mathrm{mg} / \mathrm{m}^{2}$ (cohort 1 ), were allowed, and patients experiencing Grade 3 toxicity 


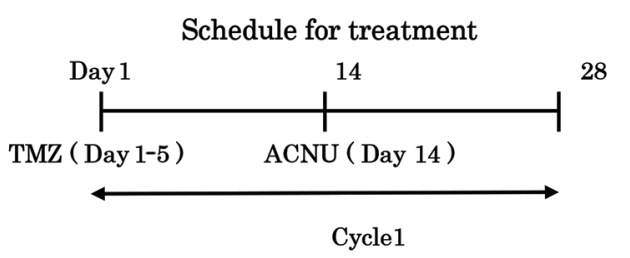

Phase I : ( Standard $3+3$ design )

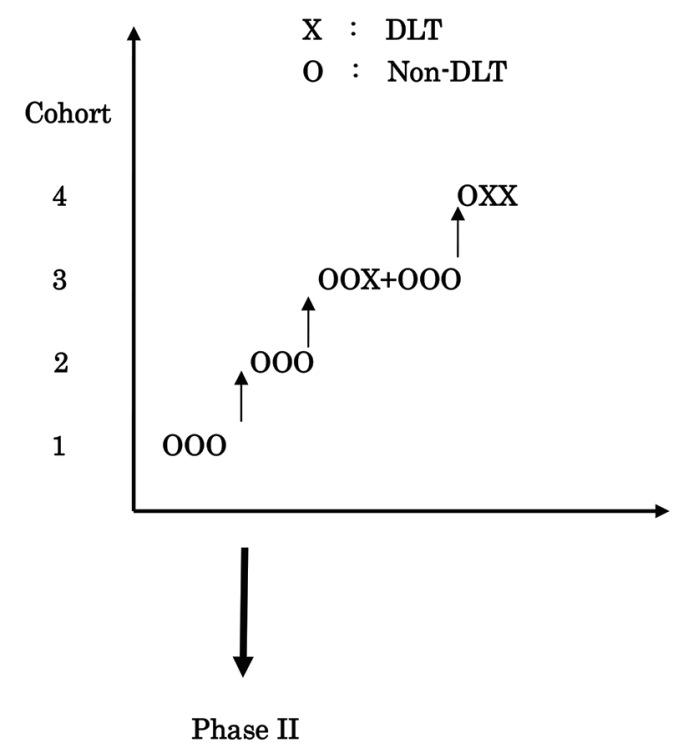

Six patients from the cohort 3 of Phase $1+34$ additional patients

Fig. 1 Schema of Phase I/II study of Temozomomide (TMZ) plus Nimustine (ACNU) DLT; Dose Limiting Toxicity. Cohort 1-TMZ $150 \mathrm{mg} / \mathrm{m}^{2} /$ day (Day 1-5) + ACNU $30 \mathrm{mg} /$ $\mathrm{m}^{2} /$ day (Day 14) Cohort 2-TMZ $150 \mathrm{mg} / \mathrm{m}^{2} / \mathrm{day}$ (Day 1-5) + ACNU $35 \mathrm{mg} / \mathrm{m}^{2} /$ day (Day 14) Cohort 3-TMZ $150 \mathrm{mg} /$ $\mathrm{m}^{2} /$ day (Day 1-5) + ACNU $40 \mathrm{mg} / \mathrm{m}^{2} /$ day (Day 14) Cohort 4-TMZ $150 \mathrm{mg} / \mathrm{m}^{2} /$ day (Day 1-5) + ACNU $45 \mathrm{mg} / \mathrm{m}^{2} / \mathrm{day}$ (Day 14).

of any type after two dose reductions were removed from the study. TMZ was administered at the dose of $150 \mathrm{mg} / \mathrm{m}^{2}$ in this study.

OS and TTP were calculated by the KaplanMeier product limit method. Overall survival was calculated from date of diagnosis to date of death or last follow-up. TTP was calculated from the start of chemotherapy until radiographic progression, clinical deterioration, or last follow-up. PFS was calculated at 6 and 12 months.

\section{Response Evaluation}

Response was assessed using a modification of the Macdonald criteria. ${ }^{20)}$ We compared baseline MR images obtained in a week before every course of chemotherapy, while also considering any changes on the neurological examination and the dose of steroids. In brief, CR was defined as the disappearance of all enhanced tumors at least 1 month after they had appeared on the last MR image obtained, with no corticosteroids and no neurological deterioration. Partial response was defined as an over $50 \%$ reduction in lesion size (the product of the largest perpendicular diameters). This response had to be maintained for at least 1 month without either neurological deterioration or an increased dose of corticosteroids. No response was defined as no change in tumor size for a minimum interval of 4 weeks or a change in tumor size after 1 month that did not qualify as CR, PR, or progressive disease. Progressive disease was defined by the following: any new tumor or over $25 \%$ increase in lesion size, a deterioration in the patient's neurological status, or stable neurological status on an increased dose of steroids. Unequivocal evidence of recurrence or progression of the disease on MR imaging was also required; acceptable evidence was disease progression on 2 subsequent MR images separated by at least 1 month apart. A multidisciplinary team consisting of a neurosurgeon, a neuroradiologist, a neurooncologist, and a radiotherapist evaluated the images.

\section{Treatment toxicity}

Toxicity monitoring was performed in patients on all treatment cycles, according to the NCI common toxicity criteria (version 4.0). A physical examination, complete blood count, urinalysis, and biochemistry profile were performed every cycle. Weekly hematological tests and serum chemistries were also required.

\section{Results}

\section{Patient characteristics}

Forty-nine patients were enrolled in this phase I/II study. Table 1 shows in patient characteristics. Fifteen patients with recurrent malignant gliomas were enrolled and treated in phase I. Three patients each were treated at cohort 1,2 and 4; six patients were treated at cohort 3 . In phase II, cohort 3 was expanded to include additional 34 patients, ensuring that 40 patients were treated at the dose of phase II (MTD), which was established at the cohort 3 of phase I. In Phase I/II, $73 \%$ of patients (36 of 49 ) had glioblastoma, and $22 \%$ (11 of 49 ) had anaplastic astrocytoma, $4 \%$ (2 of 49 ) had anaplastic oligodendroglioma. Eighty percent (39 of 49) of patients had a KPS score of 70 or better at enrollment. In total patients, median time from first diagnosis to enrollment at recurrence was 76 weeks (48-322 weeks). No surgery at last relapse on enrollment is $78 \%$ ( 38 of 49 cases). Thirty-eight percent of patients (18 of 49) had received two 
Table 1 Patient characteristics

\begin{tabular}{|c|c|c|c|c|c|c|c|}
\hline & \multirow{3}{*}{$\frac{\text { Total }}{(\mathrm{n}=49)}$} & \multicolumn{4}{|c|}{ Phase I $(n=15)$} & \multicolumn{2}{|c|}{ Phase II } \\
\hline & & \multirow{2}{*}{$\frac{\text { Cohort } 1}{(n=3)}$} & \multirow{2}{*}{$\begin{array}{c}\text { Cohort } 2 \\
(n=3)\end{array}$} & \multirow{2}{*}{$\begin{array}{c}\text { Cohort } 3 \\
(n=6)\end{array}$} & \multirow{2}{*}{$\frac{\text { Cohort } 4}{(n=3)}$} & \multicolumn{2}{|c|}{$\mathrm{TMZ}\left(150 \mathrm{mg} / \mathrm{m}^{2}\right)+\mathrm{ACNU}\left(40 \mathrm{mg} / \mathrm{m}^{2}\right)$} \\
\hline & & & & & & $\operatorname{MG}(\mathrm{n}=40)^{*}$ & GBM (n = 33) \\
\hline \multicolumn{8}{|l|}{ Age } \\
\hline Median & 50 & 34 & 47 & 54 & 57 & 50 & 52 \\
\hline Range & $22-75$ & $27-45$ & $47-63$ & $42-75$ & $45-67$ & $22-75$ & $27-75$ \\
\hline$<50$ & 27 & 3 & 2 & 2 & 1 & 20 & 15 \\
\hline$\geqq 50$ & 24 & 0 & 1 & 4 & 2 & 20 & 18 \\
\hline \multicolumn{8}{|l|}{ Sex } \\
\hline Male & 33 & 2 & 2 & 4 & 1 & 28 & 25 \\
\hline Female & 16 & 1 & 1 & 2 & 2 & 12 & 8 \\
\hline \multicolumn{8}{|l|}{ Histology } \\
\hline Glioblastoma & 36 & 1 & 1 & 5 & 1 & 33 & 33 \\
\hline Anaplastic astrocytoma & 11 & 1 & 1 & 1 & 2 & 7 & 0 \\
\hline $\begin{array}{l}\text { Anaplastic } \\
\text { oligodendroglioma }\end{array}$ & 2 & 1 & 1 & 0 & 0 & 0 & 0 \\
\hline \multicolumn{8}{|l|}{$\begin{array}{l}\text { Karnofsky performance } \\
\text { status }\end{array}$} \\
\hline 100 & 0 & 0 & 0 & 0 & 0 & 0 & 0 \\
\hline 90 & 8 & 1 & 2 & 1 & 0 & 5 & 4 \\
\hline 80 & 13 & 0 & 0 & 1 & 1 & 12 & 10 \\
\hline 70 & 18 & 2 & 1 & 2 & 1 & 14 & 11 \\
\hline 60 & 10 & 0 & 0 & 2 & 1 & 9 & 8 \\
\hline \multicolumn{8}{|l|}{ Time from first diagnosis } \\
\hline \multicolumn{8}{|l|}{ to enrollment (weeks) } \\
\hline Median & 76 & 49 & 122 & 64 & 106 & 71 & 65 \\
\hline Range & $48-322$ & $48-59$ & $81-144$ & $48-5$ & $88-272$ & $48-322$ & $48-258$ \\
\hline \multicolumn{8}{|c|}{ Salvage surgery at last relapse } \\
\hline Gross total resection & 4 & 0 & 0 & 0 & 0 & 4 & 3 \\
\hline Partial resection & 7 & 0 & 0 & 0 & 0 & 7 & 7 \\
\hline No surgery & 38 & 3 & 3 & 6 & 3 & 29 & 23 \\
\hline \multicolumn{8}{|l|}{$\begin{array}{l}\text { Prior chemotherapy } \\
\text { regimens }\end{array}$} \\
\hline TMZ alone & 31 & 3 & 1 & 5 & 3 & 24 & 17 \\
\hline TMZ followed by ICE & 5 & 0 & 0 & 0 & 0 & 5 & 5 \\
\hline TMZ followed by Bev & 13 & 0 & 2 & 1 & 0 & 11 & 11 \\
\hline
\end{tabular}

Bev: Bevacizumab, GBM: Glioblastoma, ICE: Ifosfamide carboplatin etoposide, MG: Malignant gliomas, TMZ: Temozolomide. The dose at Cohort 3: TMZ $\left(150 \mathrm{mg} / \mathrm{m}^{2}\right)+$ ACNU $\left(40 \mathrm{mg} / \mathrm{m}^{2}\right)$. ${ }^{*}$ Phase II $(\mathrm{n}=40)$ includes 6 patients from cohort 3 of phase I.

prior systemic chemotherapy regimens, namely, those were second-relapsed.

\section{Safety and tolerability}

Phase I. TMZ was administered at the dose of $150 \mathrm{mg} / \mathrm{m}^{2}$ (Day 1-5). ACNU was at four various cohorts (Day 14). Three patients at $30 \mathrm{mg} / \mathrm{m}^{2}$ (cohort 1), 3 at $35 \mathrm{mg} / \mathrm{m}^{2}$ (cohort 2), 6 at $40 \mathrm{mg} / \mathrm{m}^{2}$ (cohort 3 ), and 3 at $45 \mathrm{mg} / \mathrm{m}^{2}$ (cohort 4). One patient at $40 \mathrm{mg} / \mathrm{m}^{2}$ of ACNU (cohort 3 ) developed a grade 3 neutropenia; according to a standard $3+3$ design, another three patients were added to cohort 3 . 
No DLT was found in three another three patients at $40 \mathrm{mg} / \mathrm{m}^{2}$ of ACNU. There were one patient in Grade 3 thrombocytopenia and other in grade 3 neutropenia at $45 \mathrm{mg} / \mathrm{m}^{2}$ of ACNU (cohort 4). Two of three patients showed grade 3 neutropenia at $45 \mathrm{mg} / \mathrm{m}^{2}$ (cohort 4). Hence, one of six patients at $40 \mathrm{mg} / \mathrm{m}^{2}$ (cohort 3 ) showed a grade 3 toxicity, a 40 $\mathrm{mg} / \mathrm{m}^{2}$ of ACNU was declared as the MTD. Under $35 \mathrm{mg} / \mathrm{m}^{2}$ of ACNU, all other toxicities were grade 1 or 2 . In six patients on cohort 3 , a dose reduction from 40 to $35 \mathrm{mg} / \mathrm{m}^{2}$ of ACNU occurred in cycle 2 for one patient and in cycle 4 for other; one of these two patients required further dose reduction to $30 \mathrm{mg} / \mathrm{m}^{2}$. Prolonged hematologic toxicity led to the removal of one patient from study after cycle 5. No patient suffered a toxic mortality, although one patient died 20 weeks after study withdrawal at an outside institution from a pneumonia. None of patients developed thrombosis. After phase I, phase II was started at $40 \mathrm{mg} / \mathrm{m}^{2}$ of ACNU from cohort 3 with TMZ (150 mg/mg/day, day 1-5), every 4 weeks.

Phase II. Toxicities, which were graded based on the NCI common toxicity criteria (version 4.0), were recorded for patients treated at the dose of phase II $(n=40)$ (Table 2). Grade 3 or 4 neutropenia occurred in six patients $(15 \%)$, and grade 3 or 4 thrombocytopenia

Table 2 Toxicities (Phase II, $\mathbf{n}=\mathbf{4 0}$ )*

\begin{tabular}{lcc}
\hline & $\begin{array}{c}\text { No. of } \\
\text { patients (\%) } \\
\text { Grade 1-2 }\end{array}$ & $\begin{array}{c}\text { No. of } \\
\text { patients (\%) } \\
\text { Grade 3-4 }\end{array}$ \\
\hline Patients with toxicities & $34(85)$ & $14(35)$ \\
Anemia & $21(53)$ & $7(18)$ \\
Thrombocytopenia & $24(60)$ & $10(25)$ \\
Neutropenia & $21(53)$ & $6(15)$ \\
Lymphocytopenia & $20(30)$ & $7(18)$ \\
Nausea / Vomiting & $12(29)$ & $5(13)$ \\
Transaminase & $8(20)$ & $3(8)$ \\
Creatinine & $3(8)$ & $2(5)$ \\
Alopecia & $5(13)$ & $0(0)$ \\
Constipation & $11(28)$ & $2(5)$ \\
Thrombosis & $1(3)$ & $1(3)$ \\
Fatigue & $19(48)$ & $1(3)$ \\
Convulsion & $2(5)$ & $1(3)$ \\
Diarrhea & $4(10)$ & $0(0)$ \\
Anorexia & $4(10)$ & $0(0)$ \\
Pulmonary infection & $2(5)$ & $2(5)$ \\
Rash & $3(8)$ & $0(0)$ \\
\hline
\end{tabular}

*Phase II $(n=40)$ includes 6 patients from cohort 3 of phase I. occurred in 10 patients (25\%). A lack of appetite, nausea or constipation sometimes persisted for 1 or 2 days, although antiemetic agents were available to patients. Grade 3 or 4 hepatic dysfunction, indicated by transaminase levels, occurred in three patients $(8 \%)$. Grade 3 or 4 renal dysfunction, indicated by creatinine levels, was observed in two patients $(5 \%)$. No one had encephalopathy or auditory toxicity. Although none of the patients had Pneumocystis carinii, two patients (5\%) had a Grade 3 or 4 pulmonary infection. Nineteen patients (48\%) were alive on follow-up over 12 months. The number of treatment cycles per patient ranged from 1 to 9 . Five patients received only 1 cycle, seven received 2, 10 received 3, six received 4 , seven received 5 , and nine received over 6 . The median number of cycles per patient was 3.8 (95\% CI, 2-6 cycles).

Treatment was delayed for a median time of 1 week (recovery after 1-2 weeks) in three patients $(7 \%)$ due to Grade 3 thrombocytopenia, neutropenia, or Grade 2 infection. The most common reason for drug discontinuation were disease progression, which occurred in 23 patients (58\%), and hematologic toxicity in eight patients $(20 \%)$. Treatment was discontinued in one patient $(3 \%)$ because of a pulmonary embolism, in one because of surgery for an unrelated condition, in five $(13 \%)$ because of Grade 2 fatigue (they withdrew consent), and in one (3\%) because of pulmonary infection (Table 3). TMZ was not reduced in dose, but ACNU was often reduced in this study. Relative dose intensity in all cycles of ACNU was $87 \%$ (95\% CI, 75-100\%).

None of the deaths were considered treatment related. Twenty-one deaths were due to progression of disease and one was secondary to complications from pneumonia.

\section{Treatment responses}

In phase II, 40 patients including the cohort 3 of phase I were evaluated (Table 4). Thirty-seven patients could be assessed for treatment response

Table 3 Reasons for treatment discontinuation (Phase II, $\mathrm{n}=\mathbf{4 0})^{*}$

\begin{tabular}{lc}
\hline Reasons & $\begin{array}{c}\text { No. of } \\
\text { patients (\%) }\end{array}$ \\
\hline Disease progression & $23(58)$ \\
Hematologic toxicity & $8(20)$ \\
Grade 2 fatigue and withdrew consent & $5(13)$ \\
Thromboembolic complications & $1(3)$ \\
Required surgery for unrelated conditions & $1(3)$ \\
Pulmonary infections & $1(3)$ \\
\hline
\end{tabular}

*Phase II $(n=40)$ includes 6 patients from cohort 3 of phase I. 
because three patients underwent almost total resection at salvage surgery before this treatment. These three patients have 3,5 , and 6 months of PFS. There was 0 CR $(0 \%)$ and 4 PRs $(11 \%)$ in phase II. The overall response rate (CR + PR) was $11 \%$ (4 of 37 patients, $95 \%$ CI $4-16 \%$ ). The median duration of disease stabilization (PR + SD) in 29 patients $(78 \%)$ was 12 weeks (range 6-75 weeks). All responding patients were taking either a stable dose or no corticosteroids at the time of the best response. The rate of stable disease was $63 \%(95 \%$ CI, $54-77 \%$ ), 25 of 40 patients.

\section{Disease progression}

In 40 patients of phase II (Fig. 2), the median PFS was 13 weeks (95\% CI 7-24 weeks). PFS at 6 and 12 months after this treatment were 24\% (95\% CI $12-35 \%)$ and $8 \%$ (95\% CI 3-15\%), respectively, (Table 4). In 33 patients with GBM of phase II, the median PFS was 10 weeks (95\% CI 6-22 weeks). PFS at 6 and 12 months after this treatment were $21 \%$ (95\% CI $11-33 \%$ ) and $6 \%$ (95\% CI $2-13 \%$ ), respectively. On univariate analysis, there was no difference in the possibility of progression based on surgical treatment at relapse $(p=0.55)$, the extent of surgery $(p=0.31)$, prior to chemotherapy ( $p=$ $0.47)$, patient age $(p=0.34)$, or KPS score $(p=$ $0.45)$. On multivariate analysis, the factors predictive of disease progression were treatment response or disease stabilization attained with this therapy ( $p=0.005$ ) and the number of treatment cycles ( 1 or $2 ; p=0.007$ ). At the relapse after this treatment, eight received bevacizumab, four patients received interferon- $\beta$, five patients underwent radiosurgery, and three patients underwent salvage surgery.

\section{Overall survival}

The median survival time in 40 patients of phase II (Fig. 2), calculating from the start of this chemotherapy, was 11.8 months (95\% CI 8.2-14.5 months), and 78\% (95\% CI $67-96 \%$ ) and $49 \%$ (95\% CI $27-63 \%$ ) of the patients were alive at 6 and 12 months after the treatment, respectively (Table 4). In 33 patients with GBM of phase II, the median OS was 10.3 months (95\% CI 6.7-13.1 months). OS at 6 and 12 months after this treatment were $74 \%$ (95\% CI 63-95\%) and

Table 4 Survival, progression-free survival and response rate of temozolomide plus nimustine therapy

\begin{tabular}{|c|c|c|c|c|c|c|}
\hline & \multicolumn{4}{|c|}{ Phase I (n = 15) } & \multicolumn{2}{|c|}{ Phase II } \\
\hline & \multirow{2}{*}{$\frac{\text { Cohort } 1}{(\mathrm{n}=3)}$} & \multirow{2}{*}{$\begin{array}{c}\text { Cohort } 2 \\
(\mathrm{n}=3)\end{array}$} & \multirow{2}{*}{$\begin{array}{c}\text { Cohort } 3 \\
(\mathrm{n}=6)\end{array}$} & \multirow{2}{*}{$\begin{array}{c}\text { Cohort } 4 \\
(\mathrm{n}=3)\end{array}$} & \multicolumn{2}{|c|}{ TMZ $\left(150 \mathrm{mg} / \mathrm{m}^{2}\right)+\mathrm{ACNU}\left(40 \mathrm{mg} / \mathrm{m}^{2}\right)$} \\
\hline & & & & & $\operatorname{MG}(n=40)^{*}$ & GBM $(n=33)$ \\
\hline Median survival, months & 16 & 18 & 13 & 11 & 11.8 & 10.3 \\
\hline Range, months & $10-18$ & $7-24$ & $8-24$ & $6-17$ & $3-24$ & $3-22$ \\
\hline 1-year survival, \% & 100 & 100 & 83 & 66 & 49 & 44 \\
\hline Median PFS, weeks & 12 & 57 & 10 & 57 & 13 & 10 \\
\hline PFS-6 months, \% & 0 & 0 & 17 & 0 & 24 & 21 \\
\hline \multicolumn{7}{|l|}{ Best response } \\
\hline CR & 0 & 0 & 0 & 0 & 0 & 0 \\
\hline $\mathrm{PR}$ & 0 & 0 & 1 & 0 & 4 & 3 \\
\hline SD & 3 & 3 & 2 & 2 & 25 & 20 \\
\hline $\mathrm{PD}$ & 0 & 0 & 4 & 1 & 8 & 7 \\
\hline Non-evaluable lesions & 0 & 0 & 0 & 0 & 3 & 3 \\
\hline \multicolumn{7}{|c|}{ Duration of disease stabilization } \\
\hline \multicolumn{7}{|l|}{$(\mathrm{PR}+\mathrm{SD})$, weeks } \\
\hline Mean & 11.6 & 8.0 & 7.9 & 8.7 & 13 & 11 \\
\hline Median & 12 & 57 & 10 & 8.1 & 12 & 10 \\
\hline Range & $11-12$ & $8-22$ & $8-75$ & $4-16$ & $6-75$ & $6-59$ \\
\hline \multicolumn{7}{|l|}{ Patients on this therapy } \\
\hline for $>6$ months & 0 & 0 & 1 & 0 & 9 & 7 \\
\hline
\end{tabular}

CR: Complete response, GBM: glioblastoma, MG: Malignant gliomas, PD: Progressive disease, PFS: Progression-free survival, PR: Partial response, SD: Stable disease. Responses assessed by Macdonard's criteria on MRI. *Phase II (n = 40) includes 6 patients from cohort 3 of phase I. 


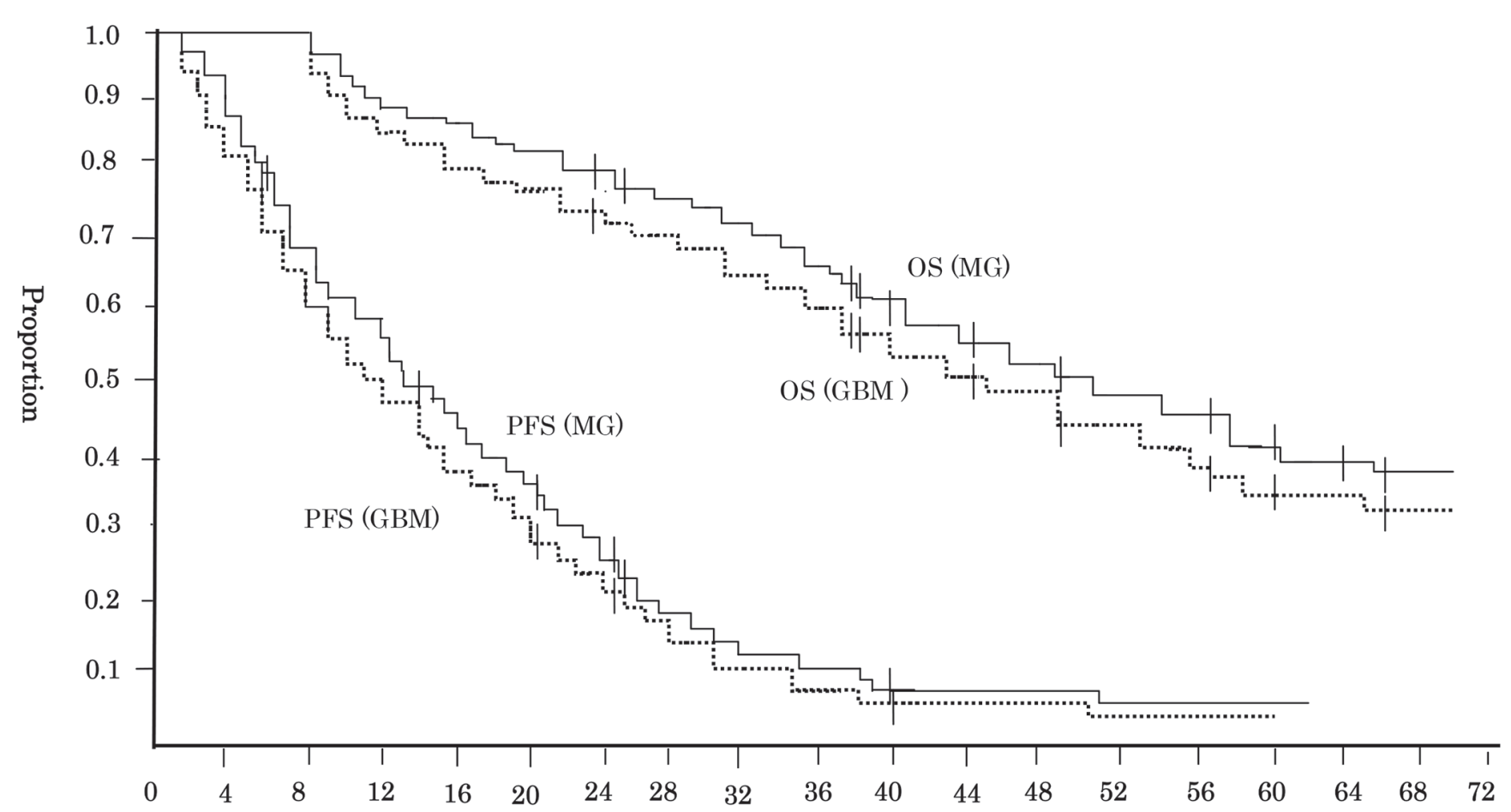

Time (weeks)

Fig. 2 Kaplan-Meier estimates of progression-free survival (PFS) and overall survival (OS) in patients with recurrent malignant gliomas and glioblastoma (GBM). Tick marks represent censored patients. GBM: glioblastoma, MG: malignant gliomas.

$44 \%$ (95\% CI 32-69\%), respectively. On univariate analysis, there was no difference in the possibility of overall survival based on surgical treatment at relapse $(p=0.55)$, the extent of surgery ( $p=$ $0.28)$, prior to chemotherapy $(p=0.30)$, patient age ( $p=0.33)$, or KPS score $(p=0.44)$. On multivariate analysis, factors predictive of OS were treatment response or disease stabilization attained with this therapy $(p=0.003)$.

\section{Discussion}

TMZ is an orally bioavailable imidazotetrazine derivative of decarbazine. ${ }^{21)}$ The active metabolite is monomethyl triazenoimidazole carboxamide, and cytotoxicity is primarily due to methylation at the 06 position of guanine. TMZ also acts as an inhibitor of DNA mismatch repair and can induce apoptosis. ${ }^{22)}$ ACNU forms a chloroethyl adduct at the $\mathrm{O6}$ position of guanine, ${ }^{10,23,24)}$ whereas TMZ appears to act by methlyation at this site. Both the methyl and chloroethyl adducts are repaired by the DNA repair protein O6-alklyguanine-DNA alkytransferase (AGT). Both TMZ and ACNU belong to alkylating agents. But these mechanisms of DNA damage between them are different. TMZ damages
DNA by base pair substation. On the other hand, ACNU bring about chromosomal deletion by interstand crosslink in double strands. The synergistic mechanism of TMZ plus ACNU may be expected. A potential therapeutic effect in tumor cells may also occur. Most commonly used agents in daily practice for malignant gliomas are nitrosoureas, particularly ACNU in Japan, and TMZ.

In schedules for administration of TMZ plus BCNU or CCNU, various types of regimens have been reported. ${ }^{11,14-16)}$ Considering compliance and conveniences of administration to patients in daily practice, we have chosen a schedule for TMZ (Day 1-5) plus ACNU (Day 14) in this study.

Toxicities in this study show that TMZ plus ACNU chemotherapy were certainly more toxic than either one (Table 2). The toxicity profile for this study was predominantly hematologic, and $22 \%$ of patients were under four cycles of therapy due to toxicities. The dose schedule for this study was selected based on this phase I study. However, it is important to note that the determination of dose-limiting toxicities and MTD in phase I study was based on the tolerance of the first cycle only. It is difficult to speculate in advance how patients may tolerate during long extended cycles in phase II. 
We should keep in mind that the necessity of toxicity assessment during several cycles in phase II study. ${ }^{25,26)}$ This is often limited because of the refractory nature of the disease and the likelihood of early progression. When ACNU is used in combination with procarbazine, $80 \mathrm{mg} / \mathrm{m}^{2}$ of ACNU was found to be too toxic. ${ }^{27)}$ When ACNU with carboplatin, etc., $60 \mathrm{mg} / \mathrm{m}^{2}$ of ACNU was moderate toxicity. ${ }^{28)}$ A dose of $80 \mathrm{mg} / \mathrm{m}^{2}$ of ACNU was also too toxic even when used as a single agent. ${ }^{27)}$ The toxicity of TMZ plus ACNU on dose escalation was myelosuppression, similar to results in reported studies of various combinations of TMZ plus BCNU. ${ }^{11,14,16)}$ Recently, RTOG 9813 reported that RT plus TMZ did not appear to significantly improve OS or PFS for anaplastic astrocytoma, compared with RT plus BCNU. RT plus TMZ was better tolerated. ${ }^{29)}$ The major toxicity in this study was also myelosuppression, and although it was tolerable, dose reductions were sometimes occurred. The toxicity of ACNU may not be so strong comparing with BCNU. ACNU is watersoluble and BCNU is lipid-soluble. The difference in properties between such agents might influence the efficacy and side effects. ${ }^{30,31)}$

Several studies have generally reported response rates under $20 \%$ and a PFS-6 under $30 \%$ in recurrent GBM (Table 5). In 33 patients with GBM of this phase II, PFS-6 was $21 \%$, which was almost equal or not inferior, and OS at 12 months was $44 \%$ which could be better than other studies. This regimen could delay the speed of tumor growth even during the progressive phase by Macdnard criteria. Some treatments including salvage administrations of bevacizumab, ${ }^{32)}$ interferon- $\beta,{ }^{41)}$ ICE (ifosfamide, carboplatine and etoposide), ${ }^{34)}$ and so on, after progression, may influence this promising OS. The methylation of the MGMT promoter and the mutation of IDH1/2 are associated with a favorable outcome after TMZ chemotherapy for patients with newly diagnosed GBM. ${ }^{35,36)}$ In this study, because of the limited tumor material obtained from surgeries, these correlative studies on the methylation of MGMT promoter and the mutation of IDH1/2 could not be performed.

This study has equal or not inferior efficacy in PFS and moderate or durable myelotoxicity but may be a promising in OS, comparing with other studies. This regimen could be an option for patients with recurrent malignant gliomas, though further study is needed.

\section{Acknowledgments}

These institutional review boards at participant hospitals have approved this protocol.: Kyoto University, Kitano Hospital, Kyoto National Hospital, Himeji National Hospital, Osaka Red Cross Hospital, Fukui Red Cross Hospital, Hikone City Hospital, Shizuoka Preferectual Hospital, Hamamatsu Rousai Hospital, Kobe Metal Hospital, Fukuoka University and Hiroshima University.

Table 5 Clinical trials in recurrent glioblastoma after temozolomide treatment

\begin{tabular}{|c|c|c|c|c|c|}
\hline Authors and year & Regimens & No. of pts & PFS-6: \% (95\% CI) & OS-12: \% (95\% CI) & Median OS (95\% CI) \\
\hline Han et al. $2014^{37}$ & TMZ (7/7) & 40 & $10(3-24)$ & $\sim 28$ (NR) & $5.4(4.2-7.7)$ \\
\hline Weller et al. $2015^{38}$ & $\mathrm{TMZ}(7 / 7)$ & 52 & $17.1(8.2-28.8)$ & $41.0(26.7-54.8)$ & $9.8(6.7-13.0)$ \\
\hline (DIRECTOR) & TMZ (21/7) & 53 & $25.5(14.3-37.3)$ & $32.7(20.2-45.9)$ & $10.6(8.1-11.6)$ \\
\hline Nagane et al. $2012^{32}$ & Bev & 31 & $33.9(19.2-48.5)$ & $34.5(20.0-49.0)$ & $10.5(8.2-12.4)$ \\
\hline \multirow[t]{2}{*}{ Friedmann et al. $2009^{39}$} & Bev & 85 & $42.6(29.6-55.5)$ & 25 (NR) & $9.2(8.2-10.7)$ \\
\hline & Bev + CPT-11 & 82 & $50.3(36.8-63.9)$ & $30(\mathrm{NR})$ & $8.7(7.8-10.9)$ \\
\hline Taal et al. $2014^{6}$ & Bev & 50 & $16(7-27)$ & $26(15-39)$ & $8(6-9)$ \\
\hline \multirow[t]{2}{*}{ (BELOB trial) } & CCNU & 46 & $13(5-24)$ & $30(18-44)$ & $8(6-11)$ \\
\hline & $\mathrm{Bev}+\mathrm{CCNU}$ & 52 & $42(29-55)$ & $48(34-61)$ & $12(8-13)$ \\
\hline Brandes et al. $2004^{40}$ & BCNU + CPT-11 & 42 & $30.3(18-51)$ & $44.1(26.4-73.6)$ & $11.4(\mathrm{NR})$ \\
\hline Reithmeier et al. $2010^{41}$ & BCNU & 35 & $13(\mathrm{NR})$ & $5(\mathrm{NR})$ & $5.5(4.5-6.5)$ \\
\hline Happold et al. $2009^{42}$ & ACNU & 32 & $20(\mathrm{NR})$ & $26(\mathrm{NR})$ & $6.7(3.35-10.1)$ \\
\hline Aoki et al. $2010^{34}$ & ICE & 42 & $35(22-50)$ & $37(27-63)$ & $10.7(7.9-13.6)$ \\
\hline This study* & $\mathrm{TMZ}+\mathrm{ACNU}$ & 33 & $21(11-33)$ & $44(32-69)$ & $10.3(6.7-13.1)$ \\
\hline
\end{tabular}

ACNU: Nimustine, BCNU: Carmustine, Bev: Bevacizumab, CCNU: Lomustine, CPT-11: Irinothecan, GBM: Glioblastoma, ICE: Ifosfamide carboplatin etoposide, NR: Not reported, OS: Overall survival, OS-12: Overall survival at 12 months, PFS-6: Progression-free survival at 6 months, pts: patients, 7/7, 7 days on / 7 days off, 21/7, 21 days on / 7 days off, TMZ: Temozolomide. *This data depends on 33 patients with glioblastoma from Phase II portion. 


\section{Conflicts of Interest Disclosure}

The authors have no personal, financial, or institutional interest in any of the drugs, materials, or devices in the article. All authors who are members of The Japan Neurosurgical Society (JNS) have registered online Self-reported COI Disclosure Statement Forms through the website for JNS members. This manuscript has no COI that should be disclosed.

\section{References}

1) Stupp R, Mason WP, van den Bent MJ, Weller M, Fisher B, Taphoorn MJ, Belanger K, Brandes AA, Marosi C, Bogdahn U, Curschmann J, Janzer RC, Ludwin SK, Gorlia T, Allgeier A, Lacombe D, Cairncross JG, Eisenhauer E, Mirimanoff RO: European Organisation for Research and Treatment of Cancer Brain Tumor and Radiotherapy Groups; National Cancer Institute of Canada Clinical Trials Group. Radiotherapy plus concomitant and adjuvant temozolomide for glioblastoma. N Engl J Med 352: 987-96, 2005

2) Le Rhun E, Taillibert S, Chamberlain MC: Anaplastic glioma: current treatment and management. Expert Rev Neurother 15: 601-620, 2015

3) Wick W, Hartmann C, Engel C, Stoffels M, Felsberg J, Stockhammer F, Sabel MC, Koeppen S, Ketter R, Meyermann R, Rapp M, Meisner C, Kortmann RD, Pietsch T, Wiestler OD, Ernemann U, Bamberg M, Reifenberger G, von Deimling A, Weller M: NOA-04 randomized phase III trial of sequential radiochemotherapy of anaplastic glioma with procarbazine, lomustine, and vincristine or temozolomide. J Clin Oncol 27: 5874-5880, 2009

4) Chinot OL, Wick W, Mason W, Henriksson R, Saran F, Nishikawa R, Carpentier AF, Hoang-Xuan K, Kavan P, Cernea D, Brandes AA, Hilton M, Abrey L, Cloughesy T: Bevacizumab plus radiotherapytemozolomide for newly diagnosed glioblastoma. $N$ Engl J Med 370: 709-722, 2009

5) Gilbert MR, Dignam JJ, Armstrong TS, Wefel JS, Blumenthal DT, Vogelbaum MA, Colman H, Chakravarti A, Pugh S, Won M, Jeraj R, Brown PD, Jaeckle KA, Schiff D, Stieber VW, Brachman DG, WernerWasik M, Tremont-Lukats IW, Sulman EP, Aldape KD, Curran WJ Jr, Mehta MP: A randomized trial of bevacizumab for newly diagnosed glioblastoma. N Engl J Med 370: 699-708, 2014

6) Taal W, Oosterkamp HM, Walenkamp AM, Dubbink HJ, Beerepoot LV, Hanse MC, Buter J, Honkoop AH, Boerman D, de Vos FY, Dinjens WN, Enting RH, Taphoorn MJ, van den Berkmortel FW, Jansen RL, Brandsma D, Bromberg JE, van Heuvel I, Vernhout RM, van der Holt B, van den Bent MJ: Single-agent bevacizumab or lomustine versus a combination of bevacizumab plus lomustine in patients with recurrent glioblastoma (BELOB trial): a randomised controlled phase 2 trial. Lancet Oncol 15: 943-53, 2014
7) Wick W, Brandes AA, Gorlia T, Bendszus M, Sahm F, Taal W, Taphoorn M, Domont J, Idbaih A, Campone M, Clement PM, Stupp R, Fabbro M, Dubois F, Bais C, Musmeci D, Platten M, Weller M, Golfinopoulos V, van den Bent M : Phase III trial exploring the combination of bevacizumab and lomustine in patients with first recurrence of a glioblastoma: The EORTC 26101 trial. Neuro Oncol 17: (suppl 5), 2015

8) Aoki T, Nishikawa R, Sugiyama K, Nonoguchi N, Kawabata N, Mishima K, Adachi J, Kurisu K, Yamasaki F, Tominaga T, Kumabe T, Ueki K, Higuchi F, Yamamoto T, Ishikawa E, Takeshima H, Yamashita S, Arita K, Hirano H, Yamada S, Matsutani M: A multicenter phase I/II study of the BCNU implant (Gliadel® Wafer) for Japanese patients with malignant Gliomas. Neurol Med Chir (Tokyo) 54: 290-301, 2014

9) Brem H, Piantadosi S, Burger PC, Walker M, Selker R, Vick NA, Black K, Sisti M, Brem S, Mohr G, Muller P, Morawetz R, Schold SC: Placebo-controlled trial of safety and efficacy of intraoperative controlled delivery by biodegradable polymers of chemotherapy for recurrent gliomas. The Polymer-brain Tumor Treatment Group. Lancet 345: 1008-1012, 1995

10) Büch TR, Zeller WJ: Comparative cytotoxicity of carmustine (BCNU), nimustine (ACNU) and elmustine (HeCNU) after depletion of O6-alkylguanineDNA alkyltransferase (O6-AGT). Anticancer Res 22: 697-701, 2002

11) Chang SM, Prados MD, Yung WK, Fine H, Junck L, Greenberg H, Robins HI, Mehta M, Fink KL, Jaeckle KA, Kuhn J, Hess K, Schold C: Phase II study of neoadjuvant 1, 3-bis (2-chloroethyl)-1-nitrosourea and temozolomide for newly diagnosed anaplastic glioma: a North American Brain Tumor Consortium Trial. Cancer 100: 1712-1716, 2004

12) Stewart LA: Chemotherapy in adult high-grade glioma: a systematic review and meta-analysis of individual patient data from 12 randomised trials. Lancet 359: 1011-1018, 2002

13) Tolcher AW, Gerson SL, Denis L, Geyer C, Hammond LA, Patnaik A, Goetz AD, Schwartz G, Edwards T, Reyderman L, Statkevich P, Cutler DL, Rowinsky EK: Marked inactivation of O6-alkylguanine-DNA alkyltransferase activity with protracted temozolomide schedules. Br J Cancer 88: 1004-1011, 2003

14) Barrié M, Couprie C, Dufour H, Figarella-Branger D, Muracciole X, Hoang-Xuan K, Braguer D, Martin PM, Peragut JC, Grisoli F, Chinot O: Temozolomide in combination with BCNU before and after radiotherapy in patients with inoperable newly diagnosed glioblastoma multiforme. Ann Oncol 16: 1177-1184, 2005

15) Herrlinger U, Rieger J, Koch D, Loeser S, Blaschke B, Kortmann RD, Steinbach JP, Hundsberger T, Wick W, Meyermann R, Tan TC, Sommer C, Bamberg M, Reifenberger G, Weller M: Phase II trial of lomustine plus temozolomide chemotherapy in addition to radiotherapy in newly diagnosed glioblastoma: UKT-03. J Clin Oncol 24: 4412-4417, 2006 
16) Prados MD, Yung WK, Fine HA, Greenberg HS, Junck L, Chang SM, Nicholas MK, Robins HI, Mehta MP, Fink KL, Jaeckle KA, Kuhn J, Hess KR, Schold SC: North American Brain Tumor Consortium study. Phase 2 study of BCNU and temozolomide for recurrent glioblastoma multiforme: North American Brain Tumor Consortium study. Neuro Oncol 6: 33-37, 2004

17) Hansen AR, Graham DM, Pond GR, Siu LL: Phase 1 trial design: is $3+3$ the best? Cancer Control 21: 200-208, 2014

18) Le Tourneau C, Lee JJ, Siu LL: Dose escalation methods in phase I cancer clinical trials. J Natl Cancer Inst 101: 708-720, 2009

19) Wong ET, Hess KR, Gleason MJ, Jaeckle KA, Kyritsis AP, Prados MD, Levin VA, Yung WK: Outcomes and prognostic factors in recurrent glioma patients enrolled onto phase II clinical trials. J Clin Oncol 17: 2572-2578, 1999

20) Macdonald DR, Cascino TL, Schold SC Jr, Cairncross JG: Response criteria for phase II studies of supratentorial malignant glioma. J Clin Oncol 8: 1277-1280, 1990

21) Stevens MF, Newlands ES: From triazines and triazenes to temozolomide. Eur J Cancer 29A: 1045-1047, 1993

22) Friedman HS, Johnson SP, Dong Q, Schold SC, Rasheed BK, Bigner SH, Ali-Osman F, Dolan E, Colvin OM, Houghton P, Germain G, Drummond JT, Keir S, Marcelli S, Bigner DD, Modrich P: Methylator resistance mediated by mismatch repair deficiency in a glioblastoma multiforme xenograft. Cancer Res 57: 2933-2936, 1997

23) Kondo N, Takahashi A, Ono K, Ohnishi T: DNA damage induced by alkylating agents and repair pathways. J Nucleic Acids 2010: 543531, 2010

24) Li L, Zhao L, Zhong R: Quantification of DNA interstrand crosslinks induced by ACNU in NIH/3T3 and L1210 cells using high-performance liquid chromatography/electrospray ionization tandem mass spectrometry. Rapid Commun Mass Spectrom 28: 439-447, 2014

25) Bryant J, Day R: Incorporating toxicity considerations into the design of two-stage phase II clinical trials. Biometrics 51: 1372-1383, 1995

26) Sargent DJ, Chan V, Goldberg RM: A three-outcome design for phase II clinical trials. Control Clin Trials 22: 117-125, 2001

27) Shibui S, Narita Y, Mizusawa J, Beppu T, Ogasawara K, Sawamura Y, Kobayashi H, Nishikawa R, Mishima K, Muragaki Y, Maruyama T, Kuratsu J, Nakamura H, Kochi M, Minamida Y, Yamaki T, Kumabe T, Tominaga T, Kayama T, Sakurada K, Nagane M, Kobayashi K, Nakamura H, Ito T, Yazaki T, Sasaki H, Tanaka K, Takahashi H, Asai A, Todo T, Wakabayashi T, Takahashi J, Takano S, Fujimaki T, Sumi M, Miyakita Y, Nakazato Y, Sato A, Fukuda H, Nomura K: Randomized trial of chemoradiotherapy and adjuvant chemotherapy with nimustine (ACNU) versus nimustine plus procarbazine for newly diagnosed anaplastic astrocytoma and glioblastoma (JCOG0305). Cancer Chemother Pharmacol 71: 511-521, 2013

28) Aoki T, Takahashi JA, Ueba T, Oya N, Hiraoka M, Matsui K, Fukui T, Nakashima Y, Ishikawa M, Hashimoto N: Phase II study of nimustine, carboplatin, vincristine, and interferon-beta with radiotherapy for glioblastoma multiforme: experience of the Kyoto Neuro-Oncology Group. J Neurosurg 105: 385-391, 2006.

29) Chang SM, Zhang P, Cairncross JG, Gilbert MR, Bahary JP, Dolinskas C, Aldape KD, Chakravarti A, Schiff D, Jaeckle KA, Brown PD, Barger G, Werner-Wasik M, Shih HA, Brachman D, Penas M-Prado, Robins HI, Belanger K, Schultz CJ, Mehta MP: Results of NRG oncology/RTOG 9813: A phase III randomized study of radiation therapy (RT) and temozolomide (TMZ) versus RT and nitrosourea (NU) therapy for anaplastic astrocytoma (AA). J Clin Oncol 33: 2015 (suppl; abstr 2002)

30) Harada K, Kiya K, Uosumi T: Pharmacokinetics of a new water-soluble nitrosourea derivative (ACNU) in human gliomas. Surg Neurol 15: 410-414, 1981

31) Levin VA, Hoffman W, Weinkam RJ: Pharmacokinetics of BCNU in man: a preliminary study of 20 patients. Cancer Treat Rep 62: 1305-1312, 1978.

32) Nagane M, Nishikawa R, Narita Y, Kobayashi H, Takano S, Shinoura N, Aoki T, Sugiyama K, Kuratsu J, Muragaki Y, Sawamura Y, Matsutani M: Phase II study of single-agent bevacizumab in Japanese patients with recurrent malignant glioma. Jpn J Clin Oncol 42: 887-895, 2012

33) Wakabayashi T, Kayama T, Nishikawa R, Takahashi H, Hashimoto N, Takahashi J, Aoki T, Sugiyama K, Ogura M, Natsume A, Yoshida J: Multicenter phase I trial of combination therapy with interferon- $\beta$ and temozolomide for high-grade gliomas (INTEGRA study): the final report. J Neurooncol 104: 573-577, 2011

34) Aoki T, Mizutani T, Nojima K, Takagi T, Okumura R, Yuba Y, Ueba T, Takahashi JA, Miyatake S, Nozaki K, Taki W, Matsutani M: Phase II study of ifosfamide, carboplatin, and etoposide in patients with a first recurrence of glioblastoma multiforme. J Neurosurg 112: 50-56, 2010

35) Hegi ME, Diserens AC, Gorlia T, Hamou MF, de Tribolet N, Weller M, Kros JM, Hainfellner JA, Mason W, Mariani L, Bromberg JE, Hau P, Mirimanoff RO, Cairncross JG, Janzer RC, Stupp R: MGMT gene silencing and benefit from temozolomide in glioblastoma. N Engl J Med 352: 997-1003, 2005

36) Yan H, Parsons DW, Jin G, McLendon R, Rasheed BA, Yuan W, Kos I, Batinic-Haberle I, Jones S, Riggins GJ, Friedman H, Friedman A, Reardon D, Herndon J, Kinzler KW, Velculescu VE, Vogelstein B, Bigner DD. IDH1 and IDH2 mutations in gliomas. $N$ Engl J Med 360: 765-773, 2009

37) Han SJ, Rolston JD, Molinaro AM, Clarke JL, Prados MD, Chang SM, Berger MS, DeSilva A, Butowski NA: Phase II trial of 7 days on/7days off 
temozolmide for recurrent high-grade glioma. Neuro Oncol 16: 1255-1262, 2014

38) Weller M, Tabatabai G, Kästner B, Felsberg J, Steinbach JP, Wick A, Schnell O, Hau P, Herrlinger U, Sabel MC, Wirsching HG, Ketter R, Bähr O, Platten M, Tonn JC, Schlegel U, Marosi C, Goldbrunner R, Stupp R, Homicsko K, Pichler J, Nikkhah G, Meixensberger J, Vajkoczy P, Kollias S, Hüsing J, Reifenberger G, Wick W: DIRECTOR Study Group. MGMT promoter methylation is a strong prognostic biomarker for benefit from dose-intensified temozolomide rechallenge in progressive glioblastoma: The DIRECTOR trial. Clin Cancer Res 21: 2057-2064, 2015

39) Friedman HS, Prados MD, Wen PY, Mikkelsen T, Schiff D, Abrey LE, Yung WK, Paleologos N, Nicholas MK, Jensen R, Vredenburgh J, Huang J, Zheng M, Cloughesy T: Bevacizumab alone and in combination with irinotecan in recurrent glioblastoma. J Clin Oncol 27: 4733-4740, 2009

40) Brandes AA, Tosoni A, Basso U, Reni M, Valduga F, Monfardini S, Amistà P, Nicolardi L, Sotti G, Ermani M: Second-line chemotherapy with irinotecan plus carmustine in glioblastoma recurrent or progressive after first-line temozolomide chemotherapy: a phase II study of the Gruppo Italiano Cooperativo di Neuro-Oncologia (GICNO). J Clin Oncol 22: 4779-4786, 2004

41) Reithmeier T, Graf E, Piroth T, Trippel M, Pinsker MO, Nikkhah G: BCNU for recurrent glioblastoma multiforme: efficacy, toxicity and prognostic factors. BMC Cancer 10: 30, 2010

42) Happold C, Roth P, Wick W, Steinbach JP, Linnebank M, Weller M, Eisele G: ACNU-based chemotherapy for recurrent glioma in the temozolomide era. J Neurooncol 92: 45-48, 2009

Address reprint requests to: Tomokazu Aoki, MD, PhD, Department of Neurosurgery, National Hospital Organization, Kyoto Medical Center, 1-1, Mukaihatacho, Fukakusa, Fushimi-ku, Kyoto 612-8555. Tel: +81-75-641-9161; Fax: +81-75-643-4325. e-mail: totorolangdom@yahoo.co.jp 